\title{
Molecular mechanism and functional role of macrophage colony-stimulating factor in follicular granulosa cells
}

\author{
ZHANG WEI, XU SONG and ZHANG ZHIFEN
}

\begin{abstract}
Department of Gynecology, Nanjing Medical University, Affiliated Hangzhou Hospital (Hangzhou First People's Hospital), Hangzhou, Zhejiang 310006, P.R. China
\end{abstract}

Received February 14, 2016; Accepted February 15, 2017

DOI: $10.3892 / \mathrm{mmr} .2017 .6857$

\begin{abstract}
Our previous demonstrated that macrophage colony-stimulating factor (M-CSF) stimulated the production of estradiol $\left(\mathrm{E}_{2}\right)$ and progesterone $(\mathrm{P})$ in luteinized granulosa cells (GCs), and that its secretion may be regulated by follicle-stimulating hormone (FSH). The present study aimed to examine the effect of M-CSF alone or with Letrozole treatment on the function of non-luteinizing granulosa cells, using the COV434 cell line, and its interaction with FSH. Human luteinized granulosa cells (LGC) were isolated from the follicular fluid of superovulated infertile patients (average age, $30.8 \pm 2.1$ years) undergoing an intracytoplasmic sperm injection. The LGC were cultured with various concentrations of recombinant human macrophage colony stimulating factor (rhM-CSF; 0, 10, 25, 50 or $100 \mathrm{ng} / \mathrm{ml}$ ), rhM-CSF+Letrozole $\left(10^{-6} \mathrm{~mol} / \mathrm{l}\right), \mathrm{rhFSH}(0,10,25,50$ or $100 \mathrm{IU} / \mathrm{ml})$, or rhFSH+Letrozole $\left(10^{-6} \mathrm{~mol} / \mathrm{l}\right) . \mathrm{E}_{2}$ concentrations in the media were measured using ELISA. The expression levels of the FSH receptor and the M-CSF receptor were detected via reverse transcription-quantitative polymerase chain reaction. Following COV434 cell treatment with M-CSF, cell proliferation was quantified using the MTS assay and protein expression was detected by western blotting. It was demonstrated that M-CSF and FSH stimulated the production of $\mathrm{E}_{2}$ The production of FSH receptors was enhanced by rhM-CSF or rhM-CSF+Letrozole in vitro in a dose-dependent manner. It was observed that rhFSH promoted the expression of the $\mathrm{M}-\mathrm{CSF}$ receptor, at a certain concentration. Proliferation of COV434 cells increased in a dose-dependent manner following treatment with RhM-CSF. Furthermore, M-CSF induced the phosphorylation of c-Jun N-terminal kinase (JNK) and p38; however, the level of $E_{2}$ in the medium was not altered when
\end{abstract}

Correspondence to: Professor Zhang Zhifen, Department of Gynecology, Nanjing Medical University, Affiliated Hangzhou Hospital (Hangzhou First People's Hospital), 261 Huansha Road, Hangzhou, Zhejiang 310006, P.R. China

E-mail: zhangzf@zju.edu.cn

Key words: macrophage colony-stimulating factor, follicle-stimulating hormone, granulosa cells, estradiol, signaling pathways the cells were pretreated with the JNK inhibitor SP600125 or the p38 inhibitor SB203580. The present study suggested that M-CSF may be important in regulating the response of GCs to gonadotropin and may have a promotive effect in the early phase of follicular development. The biological effects of M-CSF may partially be attributed to activation of the JNK and p38 signaling pathways. M-CSF may represent a novel follicular development regulator agent in the future.

\section{Introduction}

Macrophage colony-stimulating factor (M-CSF), or colony-stimulating factor-1 (CSF-1), is a member of the haematopoietic growth factor family (1), and is a primary cytokine regulating the proliferation, survival and differentiation of macrophages via interaction with the tyrosine kinase transmembrane M-CSF receptor (M-CSFR). It has previously been demonstrated that M-CSF affects various types of cells, including reproductive cells. In 1997, Witt and Pollard (2) first reported that the concentration of M-CSF was significantly greater in follicular fluid (FF), and the M-CSFR mRNA was expressed in FF-derived cells. To define the role of $\mathrm{M}-\mathrm{CSF}$ regulated macrophages in reproduction, Cohen et al (3) studied mice homozygous for a null mutation [Csfm (op)] and observed that female Csfm (op)/Csfm (op) mice had fertility defects, including extended oestrous cycles and poor ovulation rates. Nishimura et al (4) observed that gonadotropins led to a gradual increase in the serum concentration of M-CSF throughout ovarian stimulation and that high concentrations of M-CSF were associated with successful oocyte retrieval. Salmassi et al (5) revealed that the serum concentration of M-CSF increased with the growth of follicles and that a greater serum concentration of M-CSF was associated with increased in vitro fertilization (IVF) success. Takasaki et al (6) reported that during a controlled ovarian hyperstimulation cycle, follicular development was improved by concomitant administration of M-CSF and human menopausal gonadotrophin (hMG). All of these findings suggested that M-CSF is involved in the process of follicular development and ovulation.

Granulosa cells (GCs) lining the vesicular ovarian follicle are the largest cell mass in the follicle and are important in the development and maturation of oocytes, in addition to their role in the regulation of the ovarian cycle via the production and secretion of various sex hormones and cytokines. Our 
previous study demonstrated that M-CSF secretion of GCs was enhanced by follicle-stimulating hormone (FSH) and estradiol $\left(\mathrm{E}_{2}\right)$ in vitro in a dose-dependent manner; however, was unaffected by progesterone (P) (7). Conversely, M-CSF elicited the production of $\mathrm{E}_{2}$ and $\mathrm{P}$ by GCs in a dose-dependent manner, in the presence or absence of FSH (8).

One of the important signaling pathways in cells is the mitogen activated protein kinase (MAPK) pathway, which involves extracellular-regulated protein kinase (ERK1/2), c-Jun N-terminal protein kinase (JNK) and p38 kinase (p38). A previous study revealed that M-CSF induced vascular endothelial growth factor (VEGF) in vivo via activation of the MAPK/ERK signaling pathway, and that inhibition of ERK suppressed M-CSF-induced VEGF at the mRNA and protein levels (9). A further study revealed that M-CSF increased scavenger receptor-A expression and function in macrophages, which requires the specific activation of p38 MAPK; however, not ERK1/2 or JNK. Further studies are required in order to elucidate if M-CSF activates GCs via the MAPK signaling pathway (10).

The present study evaluated the interaction of M-CSF with FSH during follicular development prior to ovulation by using human luteinized granulosa cells, and the signaling pathway of M-CSF was analyzed using the COV434 primary human granulosa cell tumor cell line.

\section{Materials and methods}

Patients. A total of 30 infertile women who had tubal (excluding hydrosalpinges) or male factor infertility from the Women's Hospital School Of Medicine, Zhejiang University (Hangzhou, China) took part in the study. The ethics committee of the Women's Hospital School Of Medicine, Zhejiang University, approved the study. Written informed consent was obtained from each study participant. Patients with endometriosis or polycystic ovary syndrome were excluded from this study. The age of the patients ranged from 26 to 33 years (median, 30.8 years). The patients undergoing intracytoplasmic sperm injection were stimulated with recombinant human (rh) FSH (EMD Serono; Merck KGaA, Darmstadt, Germany) with an initial dose of 75-300 U/d, administered by intramuscular injection (im), followed by downregulation with $1.25 \mathrm{mg}$ injected Diphereline, a gonadotropin-releasing hormone agonist (Ipsen Pharma Biotech, Signes, France), in the mid luteal phase. Follicles were aspirated $36 \mathrm{~h}$ after 5,000-10,000 IU im of human chorionic gonadotropin (Shanghai Livzon Pharmaceutical Co., Ltd., Shanghai, China), and FF was obtained from oocyte-bearing follicles.

GC collection and culture. GCs were isolated from the FF of each patient. All samples were obtained with the informed consent of the patients. The experiments were performed 3 times, and during each experiment, follicles were collected from 10 individual patients. The follicular fluids, which were obtained at the time of oocyte retrieval, were immediately centrifuged at $1,000 \mathrm{x} \mathrm{g}$ for $10 \mathrm{~min}$ at room temperature and the supernatants were removed. The top layer of white cells was withdrawn and the cells were dispersed with type I collagenase (0.1\%; Sigma-Aldrich, Merck KGaA) for 30 min in a water bath at $37^{\circ} \mathrm{C}$. The cell suspension was subsequently overlaid slowly and carefully on isopyknic 50\% Percoll (GE Healthcare Life Sciences, Uppsala, Sweden) and centrifuged at 2,000 x g for $10 \mathrm{~min}$ at room temperature. The cells were aspirated from the Percoll interphase, pooled and washed twice with PBS. The viable cells were determined by the trypan blue exclusion method (11). The cell density was adjusted to $2 \times 10^{5}$ cells $/ \mathrm{ml}$ with medium. The $1 \mathrm{ml} \mathrm{GC}$ suspensions were inoculated in triplicate into 6-well culture plates. Finally, the cells were cultured in Dulbecco's modified Eagle's medium (DMEM)/F12 (Invitrogen; Thermo Fisher Scientific, Inc., Waltham, MA, USA) supplemented with $10 \%$ fetal bovine serum (FBS; Gibco; Invitrogen; Thermo Fisher Scientific, Inc.) and incubated in a humidified incubator at $37^{\circ} \mathrm{C}$ with $95 \%$ air and $5 \% \mathrm{CO}_{2}$. Following incubation for $24 \mathrm{~h}$, the medium in each well was replaced. The cells were subsequently cultured with DMEM/F12 medium plus various concentrations of rhM-CSF $(0,10,25,50$ or $100 \mathrm{ng} / \mathrm{ml}$; R\&D Systems, Inc., Minneapolis, MN, USA), rhFSH (0, 10, 25, 50 or $100 \mathrm{IU} / \mathrm{ml}$; R\&D Systems, Inc.), rhM-CSF plus Letrozole $\left(10^{-6} \mathrm{~mol} / \mathrm{l}\right.$; Tianjin Meilun Medical Products Group, Co., Ltd., Tianjin, China) or rhFSH plus Letrozole $\left(10^{-6} \mathrm{~mol} / \mathrm{l}\right)$. The media was collected following a $24 \mathrm{~h}$ incubatory period.

$E_{2}$ assay. The $\mathrm{E}_{2}$ concentration of the supernatant was measured using an estradiol ELISA test kit (CEA461Ge; Cloud-Clone Corp. Houston, TX, USA). The testing procedures were performed according to the manufacturer's protocol.

Reverse transcription-quantitative polymerase chain reaction (RT-qPCR). The GC cells were lysed in $1 \mathrm{ml}$ RNAiso Plus (Takara Biotechnology Co., Ltd., Dalian, China) and the RNA was extracted according to the manufacturer's protocol. A total of $1 \mu \mathrm{g}$ total RNA was reverse-transcribed using the PrimeScript $^{\text {TM }}$ RT-PCR kit (Takara Biotechnology Co., Ltd.). The synthesized cDNA was amplified via RT-qPCR with SYBR Premix Ex Taq ${ }^{\mathrm{TM}}$ (Perfect Real Time; Takara Biotechnology Co., Ltd.). The oligonucleotide primer sequences were as follows: Forward, 5'-CATGTACGTTGCTATCCAGGC-3' and reverse, 5'-CTCCTTAATGTCACGCACGAT-3' for $\beta$-actin; forward, 5'-CATCATCGGATCTGTCACTGCTCTA-3' and reverse, 5'-CTCGAAGCTTGGTGAGGACAAAC-3' for FSH receptor; forward, 5'-CCAAGTTCATTCAGAGCCAGGACT A-3' and reverse, 5'-TCTGCAGGCACCAGTGTCAAG-3' for M-CSF receptor. PCR cycling was performed with the 7500 Real-Time PCR system (Applied Biosystems; Thermo Fisher Scientific. Inc.). The PCR amplification started at $95^{\circ} \mathrm{C}$ for $2 \mathrm{~min}$ and was followed by 39 cycles at $95^{\circ} \mathrm{C}$ for $10 \mathrm{sec}$ and $60^{\circ} \mathrm{C}$ for $30 \mathrm{sec}$. The comparative parameter threshold cycle (Cq) normalized to $\beta$-actin was used to quantify the mRNA expression level (12).

Measurement of the proliferation of COV434 cells. COV434 cells are immortalized GCs derived from human granulosa cell tumors. They possess numerous characteristics of normal GCs. COV434 cells were purchased from Beinachuanglian Biological Technology Co. (Beijing, China). They were cultured in DMEM/F12 (Invitrogen; Thermo Fisher Scientific, Inc.) supplemented with $10 \% \mathrm{FBS}$ and incubated at $37^{\circ} \mathrm{C}$ in a humidified incubator with $95 \%$ air and $5 \% \mathrm{CO}_{2}$. 
Table I. Effect of M-CSF and Letrozole on the production of $\mathrm{E}_{2}$ by GCs.

\begin{tabular}{|c|c|c|c|c|c|}
\hline \multirow{2}{*}{$\begin{array}{l}\text { Letrozole } \\
(\mathrm{mol} / \mathrm{l})\end{array}$} & \multicolumn{5}{|c|}{ rhM-CSF (ng/ml) } \\
\hline & 0 & 10 & 25 & 50 & 100 \\
\hline \multicolumn{6}{|c|}{$\mathrm{E}_{2}(\mathrm{pg} / \mathrm{ml})$} \\
\hline 0 & $356.44 \pm 44.33$ & $475.32 \pm 42.77^{*}$ & $580.16 \pm 41.81^{\mathrm{a}}$ & $686.48 \pm 37.49^{a}$ & $720.55 \pm 31.65^{\mathrm{a}}$ \\
\hline $10^{-6}$ & $55.07 \pm 11.47$ & $53.67 \pm 9.77$ & $58.74 \pm 13.26$ & $62.44 \pm 11.23$ & $64.54 \pm 12.76$ \\
\hline
\end{tabular}

${ }^{\text {a }}<0.05$ vs. $0 \mathrm{ng} / \mathrm{ml} \mathrm{E}_{2}$, estradiol; rh, recombinant human; M-CSF, macrophage colony-stimulation factor; GCs, granulosa cells.

Table II. Effect of FSH and Letrozole on the production of $\mathrm{E}_{2}$ by GCs.

\begin{tabular}{|c|c|c|c|c|c|}
\hline \multirow{2}{*}{$\begin{array}{l}\text { Letrozole } \\
(\mathrm{mol} / \mathrm{l})\end{array}$} & \multicolumn{5}{|c|}{ rhFSH (IU/ml) } \\
\hline & 0 & 10 & 25 & 50 & 100 \\
\hline \multicolumn{6}{|c|}{$\mathrm{E}_{2}(\mathrm{pg} / \mathrm{ml})$} \\
\hline 0 & $443.42 \pm 34.36$ & $715.29 \pm 21.92^{\mathrm{a}}$ & $815.82 \pm 55.33^{\mathrm{a}}$ & $963.32 \pm 74.06^{\mathrm{a}}$ & $1154.24 \pm 70.5^{\mathrm{a}}$ \\
\hline $10^{-6}$ & $65.53 \pm 13.15$ & $67.01 \pm 11.68$ & $63.28 \pm 13.01$ & $69.36 \pm 12.00$ & $74.18 \pm 11.31$ \\
\hline
\end{tabular}

${ }^{\mathrm{a}} \mathrm{P}<0.05$ vs. $0 \mathrm{ng} / \mathrm{ml} . \mathrm{E}_{2}$, estradiol; rh, recombinant human; FSH, follicle-stimulating hormone; GCs, granulosa cells.

To assess cell proliferation, COV434 cells in the exponential growth phase were diluted to $1 \times 10^{5} / \mathrm{ml}$ and seeded into a 96-well plate $\left(2 \times 10^{3}\right.$ cells/well). Following $24 \mathrm{~h}$, the medium was replaced, and the cells were incubated with fresh medium containing rhM-CSF $(0,10,25,50$ or $100 \mathrm{ng} / \mathrm{ml}$; $\mathrm{n}=6$ per treatment) for a further $24 \mathrm{~h}$. Following this, $20 \mu \mathrm{l}$ CellTiter 96 AQueousOne Solution (Promega Corporation, Madison, WI, USA) was added to each well for $4 \mathrm{~h}$ at $37^{\circ} \mathrm{C}$. The absorbance was measured at a wavelength of $490 \mathrm{~nm}$ using a microplate reader (SP-Max 1800 L, Shanghai China).

Western blot analysis. Total protein of the cells in each group was extracted using radioimmunoprecipitation assay lysis buffer (Wuhan Boster Biological Technology, Ltd., Wuhan, China), and the protein concentrations were quantified using a Bicinchoninic Acid Protein Assay kit (Applygen Technologies, Inc., Beijing, China). Total proteins $(50 \mu \mathrm{g})$ were separated by $10 \%$ SDS-PAGE and electrically transferred to a polyvinylidene difluoride membrane (EMD Millipore, Billerica, MA, USA). Following blocking of the membrane in 5\% non-fat milk at room temperature for $1 \mathrm{~h}$, diluted primary antibodies (mouse anti-human p-JNK $(1: 1,000 ; 9255 \mathrm{~s})$, rabbit anti-human p-ERK1/2 $(1: 1,000 ; 4370 s)$ and anti-phospho-p38 monoclonal antibody $(1: 1,000 ; 4511 s)$ (all from CST Biological Reagents Company Limited- Shanghai, China) were added, and the membrane was incubated at $4^{\circ} \mathrm{C}$ overnight. Subsequently, horseradish peroxidase (HRP)-conjugated secondary antibody [Goat anti-mouse (1:5,000; BA1050) or sheep anti-rabbit (1:5,000; BA1054) (both from Beyotime Institute of Biotechnology,
Haimen, China)] was added to the membrane and incubated at room temperature for $45 \mathrm{~min}$. Blots were visualized with Enhanced Chemiluminescence substrate (Immobilon ${ }^{\mathrm{TM}}$ Western Chemiluminescent HRP Substrate; Merck KGaA). The expression level of each protein was estimated using $\beta$-actin as the internal reference.

Statistical analysis. Statistical analysis was performed using SPSS 19.0 (IBM SPSS, Armonk, NY, USA). Data were expressed as the mean \pm standard deviation of three independent experiments. Multiple comparisons were performed by one-way analysis of variance and Tukey's test. $\mathrm{P}<0.05$ was considered to indicate a statistically significant difference.

\section{Results}

Production of $E_{2}$ by GCs increases with stimulation from FSH, M-CSF and decreases in presence of oestrogen synthesis inhibitor Letrozole. Following the addition of various concentrations of rhM-CSF $(0,10,25,50$ or $100 \mathrm{ng} / \mathrm{ml})$ or $\mathrm{rhFSH}(0,10,25,50$ or $100 \mathrm{IU} / \mathrm{ml})$ to the cultured GCs, the $\mathrm{E}_{2}$ levels increased in a dose-dependent manner $\left(\mathrm{P}<0.05\right.$; Tables I and II). The $\mathrm{E}_{2}$ levels following rhM-CSF treatment ranged from a 1.33-2.02 fold increase and levels following rhFSH treatment ranged from a 1.61-2.6 -fold increase, compared with baseline. Following the combined treatments with the oestrogen synthesis inhibitor Letrozole $\left(10^{-6} \mathrm{mmol} / \mathrm{l}\right)$, the concentrations of $\mathrm{E}_{2}$ decreased, and there was no significant difference between the two groups (Tables I and II). 


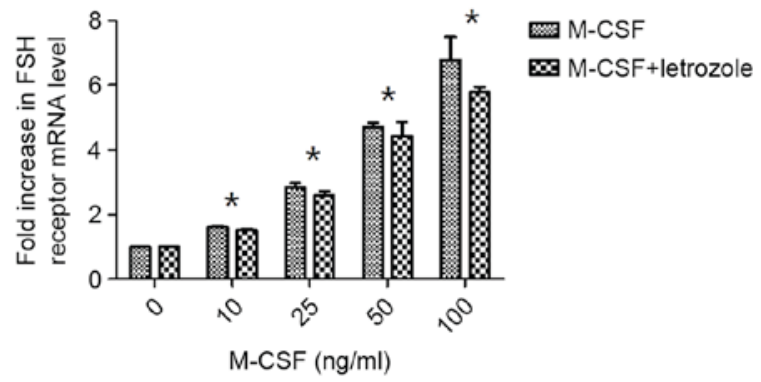

Figure 1. FSH receptor levels are increased by M-CSF in a dose-dependent manner in the presence and the absence of Letrozole. The proliferation of FSH receptors was slightly reduced following the addition of Letrozole; however, there wa s no statistically significant difference compared with the absence of Letrozole. Increased FSH receptor mRNA expression by M-CSF with or without Letrozole was significant compared with the control when its concentration reached $>10 \mathrm{ng} / \mathrm{ml}$. Data are expressed as the mean \pm standard deviation. ${ }^{*} \mathrm{P}<0.05$ vs. $0 \mathrm{ng} / \mathrm{ml}$. M-CSF, macrophage colony-stimulating factor; FSH, follicle-stimulating hormone.

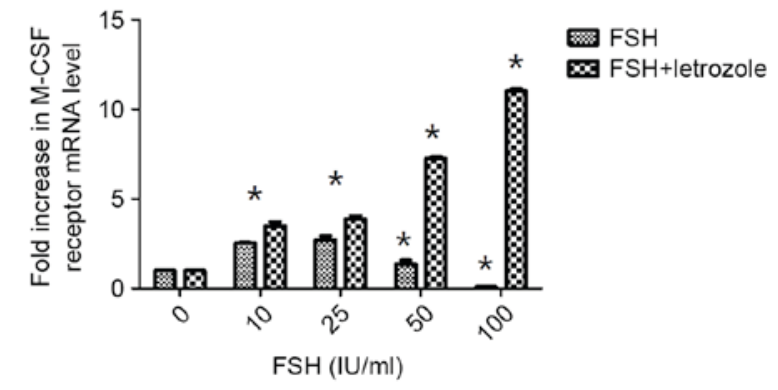

Figure 2. Optimum concentration of FSH for increasing the production of M-CSF was 10 to $25 \mathrm{IU} / \mathrm{ml}$. mRNA expression levels of M-CSF receptor following treatment with FSH, in the presence or absence of Letrozole, as assessed by reverse transcription-quantitative polymerase chain reaction. Data are expressed as the mean \pm standard deviation. ${ }^{*} \mathrm{P}<0.05$ vs. $0 \mathrm{IU} / \mathrm{ml}$. $\mathrm{M}-\mathrm{CSF}$, macrophage colony-stimulating factor; FSH, follicle-stimulating hormone.

Effects of M-CSF on FSH receptor expression differ following inhibition of $E_{2}$ synthesis by Letrozole. The expression levels of the FSH receptor were demonstrated to increase with addition of M-CSF in a dose-dependent manner, in the presence and absence of Letrozole. However, with or without the addition of Letrozole, no significant differences were observed following treatment with rhM-CSF. The expression of the FSH receptor was slightly reduced when Letrozole was added to the culture medium; however, there were no significant differences compared with the absence of Letrozole $(\mathrm{P}>0.05)$. Increases in FSH receptor production by M-CSF with or without Letrozole became significant compared with the control at $>10 \mathrm{ng} / \mathrm{ml},(\mathrm{P}<0.05$; Fig. 1).

Effects of FSH on M-CSF receptor expression following inhibition of $E_{2}$ synthesis by Letrozole. As presented in Fig. 2, when rhFSH was added to the culture medium at different concentrations, M-CSFR mRNA expression levels increased. There were significant differences in M-CSFR concentrations compared with the control when the rhFSH concentration was 10 to $25 \mathrm{IU} / \mathrm{ml}(\mathrm{P}<0.05)$. However, this effect diminished with increasing concentrations of rhFSH and even reversed at the greatest concentration (Fig. 2). Therefore, FSH may regulate

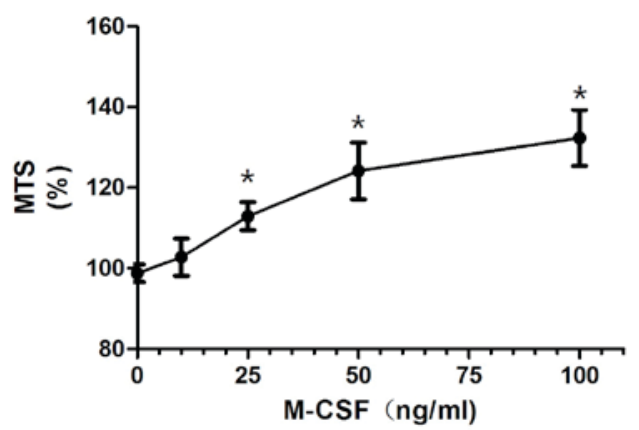

Figure 3. Proliferation of cultured COV434 cells was measured by the MTS assay. When the M-CSF concentration was $25 \mathrm{ng} / \mathrm{ml}$, the proliferation of COV434 cells significantly increased. "P<0.05 vs. $0 \mathrm{ng} / \mathrm{ml}$. M-CSF, macrophage colony-stimulating factor.

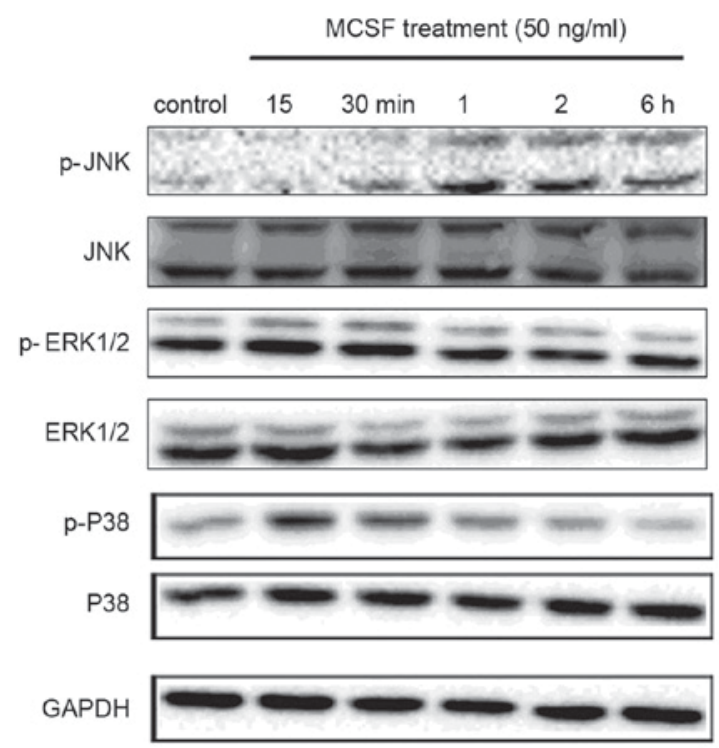

Figure 4. Western blot analysis of MAPKs in COV434 cells treated with M-CSF. Representative western blot images of protein expression levels of p-JNK, JNK, p-ERK1/2, ERK1/2, p-p38 and p38. GAPDH served as an internal control. MAPK, mitogen activated protein kinase; JNK, c-Jun N-terminal protein kinase; p, phosphorylated; M-CSF, macrophage colony-stimulating factor; ERK1/2, extracellular regulated protein kinase.

the production of M-CSF in the follicular phase. However, rhFSH administered in combination with Letrozole increased M-CSFR expression levels in a dose-dependent manner.

M-CSF promotes the proliferation of granulosa cells. The COV434 cell line, which was established from a primary human granulosa cell tumor, was used to test the effect of $\mathrm{M}-\mathrm{CSF}$ on the proliferation of granulosa cells. At $25 \mathrm{ng} / \mathrm{ml}$ rhM-CSF, the proliferation of COV434 cells increased significantly compared with the control (112.89\%; P<0.05; Fig. 3). An increase in the rhM-CSF concentration to $50 \mathrm{ng} / \mathrm{ml}$ resulted in the proliferation of granulosa cells increasing to $124.14 \%$ and then to $132.32 \%$ at $100 \mathrm{ng} / \mathrm{ml}$, which indicated that M-CSF promoted the proliferation of granulosa cells.

Activation of the biomarkers in the MAPK signaling pathway following M-CSF exposure. The MAPK signaling pathways 
A

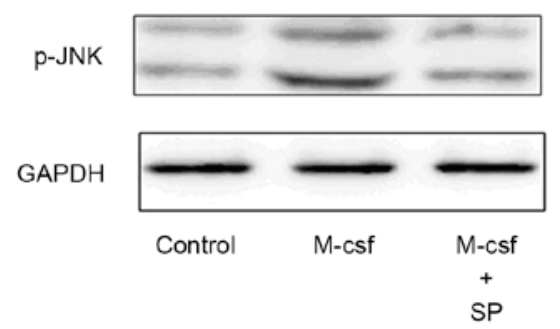

B

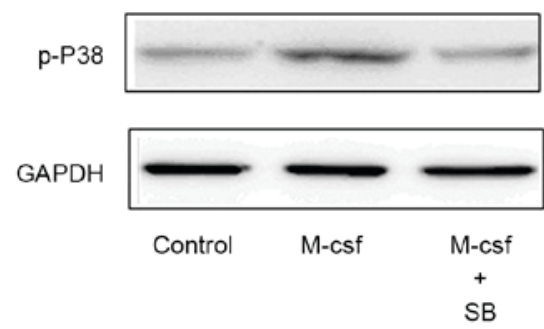

Figure 5. Western blot analysis of the expression of MAPKs in COV434 cells pretreated with MAPK inhibitors for 30 min. Representative western blot images following treatment with (A) the JNK MAPK inhibitor SP and (B) the p38 MAPK inhibitor SB. GAPDH served as an internal control. MAPK, mitogen activated protein kinase; JNK, c-Jun N-terminal protein kinase; p38, p38 kinase; p, phosphorylated; M-CSF, macrophage colony-stimulating factor; SP, SP600125; SB, SB203580.

are important for cells to respond to numerous extracellular signals. To investigate the underlying mechanisms involved in the effect of M-CSF on GCs, the present study examined the phosphorylation levels of various MAPK family proteins (ERK, p38 and JNK) in COV434 cells via western blotting. Cells were treated with $50 \mathrm{ng} / \mathrm{ml} \mathrm{rhM-CSF}$ for 0,15 or $30 \mathrm{~min}$, or 1, 2 or $6 \mathrm{~h}$. Phosphorylation of the MAPKs p38 and JNK was stimulated by rhM-CSF in COV434 cells in a time-dependent manner; however, there was no marked activation of the ERK1/2 pathway. Phosphorylation of JNK peaked at $1 \mathrm{~h}$ and that of $\mathrm{p} 38$ peaked at $15 \mathrm{~min}$, then declined (Fig. 4). Pretreating the cells with the p38 MAPK inhibitor SB203580 $(10 \mu \mathrm{M})$ or the JNK MAPK inhibitor SP600125 $(20 \mu \mathrm{M})$ blocked the activation of the corresponding MAPKs (Fig. 5). However, compared with the control group, the differences in oestrogen levels in the control, M-CSF+SB and $\mathrm{M}-\mathrm{CSF}+\mathrm{SP}$ groups were not statistically significant $(418.7 \pm 60.2,406.28 \pm 58.3$ and $420.23 \pm 54.84 \mathrm{pg} / \mathrm{ml}$, respectively; $\mathrm{P}>0.05$ ).

\section{Discussion}

It is traditionally believed that ovarian functions are primarily controlled by gonadotropins secreted from the pituitary gland. This explanation has recently been challenged by novel findings that suggest the products generated from the ovary itself, including growth factors and cytokines, are able to modulate follicular development (13). A growing body of evidence suggests that the ovary is a site of inflammatory reaction (14). In addition, numerous cells in the ovary produce cytokines independently of the presence of leukocytes, thus ovaries are sites of cytokine action and production. There is substantial evidence that cytokines are involved in the ovarian control of follicular development, and they are considered to be important regulators of steroidogenesis and gamete production. The importance of cytokines in reproduction is receiving increasing attention (15).

M-CSF is an important cytokine that may be produced by a variety of cells. In addition to regulating proliferation (16), differentiation and migration of tissue macrophages, M-CSF is important for the maintenance of ovarian function and the promotion of sex hormone secretion (17). Various investigators have demonstrated that M-CSF may promote early embryonic development (18). In numerous tissues of osteopetrotic $\left(\mathrm{Csfm}^{\mathrm{op}} / \mathrm{Csfm}^{\mathrm{op}}\right)$ mice, which have a naturally occurring null mutation in the M-CSF gene, macrophages are severely depleted (19). The M-CSF-deficient mice have extended oestrous cycles (14 days vs. 4-5 days in wild-type mice) and significantly reduced ovulation rates compared with their wild-type counterparts. However, the extended cycles returned to normal and the number of ovulated ova markedly increased following daily M-CSF administration. The number of antral and mature follicles in the pro-estrous ovary was substantially reduced in op/op mice than in control mice and increased following daily M-CSF administration $(20,21)$. It was previously demonstrated that the proliferation capacity of GCs in antral follicles was reduced in op/op mice; however, was elevated following daily M-CSF administration. The numbers of GCs and macrophages in the antral follicles were significantly decreased in op/op mice and were increased following M-CSF treatment (22). These results indicated that M-CSF is extensively involved in the process of folliculogenesis and ovulation.

Our previous study demonstrated that GCs produced M-CSF, and that M-CSF induced a significant increase of $\mathrm{E}_{2}$ and $\mathrm{P}$ secretion from luteinized GCs in a dose-dependent manner (23). The present study verified these conclusions and furthermore, investigated the interactions among M-CSF, FSH and $\mathrm{E}_{2}$. The results demonstrated that low concentrations of FSH increased the expression of M-CSFR; however, this was reversed at high concentrations. To eliminate the effect of high oestrogen levels in the culture medium, the oestrogen synthesis inhibitor Letrozole was added. The results revealed that with increasing concentrations of FSH, M-CSF receptor mRNA expression increased, suggesting that FSH promoted the expression of M-CSFR, whereas high levels of oestrogen inhibited this effect. However, the combination of M-CSF with the receptor may produce biological effects; therefore, it was hypothesized that FSH accelerates the production of M-CSF to enhance follicular development in the early phase; however, in the late phase, this effect is inhibited with the increase of the oestrogen concentration, to avoid excessive production of $\mathrm{M}-\mathrm{CSF}$ when the follicle has reached a certain stage. Based on the characteristics of M-CSF secretion and its important role in follicular development and ovulation, it has been proposed that the M-CSF level in infertile patients may be used as a predictor of the success of assisted reproductive therapy (5).

Follicular development is regulated by gonadotropins; a high concentration of which may recruit more follicles. The present study revealed that M-CSF had a role in promoting 
the production of FSHR in GCs, and this effect appeared to be dose-dependent. FSH is the most important promotor in the development of the ovarian follicle prior to ovulation. This finding indicated that M-CSF may sensitize GCs to the stimulatory effect of FSH and assist in follicular growth. Chakraborty et al (24) suggested that FSHR is expressed in the foetal hamster ovary to account for FSH-induced primordial follicle formation and cyclic AMP production. It was previously demonstrated that M-CSF facilitated the production of $\mathrm{E}_{2}$. To investigate if the alteration of FSHR is directly affected by M-CSF, Letrozole was added to inhibit the effect of oestrogen, and the same results were observed. The present study suggested that M-CSF may act directly on FSHR.

Takasaki et al (6) studied the benefit of M-CSF adjuvant therapy for poor responders during a controlled ovarian hyperstimulation cycle and suggested that concomitant administration of M-CSF and hMG improved follicle development, particularly in patients with low serum CSF-1 levels in the early follicular phase. This demonstrated the complementary effect between gonadotropin and M-CSF, and verified the feasibility of M-CSF in clinical treatment.

M-CSFR is the primary receptor for M-CSF. The binding of M-CSF to M-CSFR leads to the activation of cell signaling pathways, including the Janus kinase/signal transducer and activator of transcription, phosphoinositide 3-kinase, MAPK, diacylglycerol/protein kinase $\mathrm{C}$ and S-locus receptor kinase signaling pathways $(25,26)$. The present study revealed that M-CSF induced phosphorylation of JNK and p38. Furthermore, the oestrogen level in COV434 cells treated with M-CSF was not reduced when the cells were pretreated with the JNK inhibitor SP600125 or the P38 inhibitor SB203580. These results implied that JNK and p38 signaling is involved in the function of M-CSF. However, other signaling pathways may be involved, suggesting that further investigation is required to fully elucidate the underlying mechanism.

In conclusion, M-CSF is important in regulating the response of GCs to gonadotropin, which may have a promotive effect in the early phase of follicular development. Its functional effect may occur in part due to activation of the JNK and p38 signaling pathways. Further studies are required in order to fully elucidate the association between M-CSF and GCs in animal models and to identify if M-CSF may potentially be used as a novel follicular development regulator in the future.

\section{Acknowledgements}

The present study was supported by the Science Foundation of Zhejiang Province (grant no. Y2090796) and the National Natural Science Foundation of China (grant no. 31470078).

\section{References}

1. Clark SC and Kamen R: The human hematopoietic colony-stimulating factors. J Science 236: 1229-1237, 1987.

2. Witt BR and Pollard JW: Colony stimulating factor-1 in human follicular fluid. J Fertil Steril 68: 259-264, 1997.

3. Cohen PE, Zhu L, Nishimura K, Pollard JW: Colony-stimulating factor 1 regulation of neuroendocrine pathways that control gonadal function in mice. J Endocrinology 143: 1413-1422, 2002.

4. Nishimura K, Tanaka N, Kawano t, Matsuura K and Okamura H: Change in macrophage colony-stimulating factor concentration in serum and follicular fluid in in-vitro fertilization and embryo transfer cycles. J Fertil Steril 69: 53-57, 1998.
5. Salmassi A,Mettler L,JonatW,Buck S, Koch K and Schmutzler AG: Circulating level of macrophage colony-stimulating factor can be predictive for human in vitro fertilization outcome. J Fertil Steril 93: 116-123, 2010.

6. Takasaki A, Ohba T, Okamura Y, Honda R, Seki M, Tanaka N and Okamura $\mathrm{H}$ : Clinical use of colony-stimulating factor-1 in ovulation induction for poor responders. J Fertil Steril 90: 2287-2290, 2008.

7. Zhang Z, Salmassi A and Mettler L: Expression of macrophage colony-stimulating factor in human luteinized granulosa cells. Zhonghua Fu Chan Ke Za Zhi 37: 472-474, 2002 (In Chinese).

8. Zhang Z, Salmassi A and Mettler L: Effects of macrophage colony-stimulating factor on production of estradiol and progesterone by human luteinized granulosa cells in vitro and detection of macrophage colony-stimulating factor receptor on human luteinized granulosa cells. Zhonghua Fu Chan Ke Za Zhi 37: 338-341, 2002 (In Chinese).

9. Curry JM, Eubank TD and Roberts RD, Wang Y, Pore N, Maity A and Marsh CB: M-CSF signals through the MAPK/ERK pathway via sp1 to induce VEGF production and induces angiogenesis in vivo. J PLoS One 3: e3405, 2008.

10. Nikolic D, Calderon L, Du L and Post SR: SR-A ligand and M-CSF dynamically regulate SR-A expression and function in primary macrophage via P-38 MAPK activation. J BMC Immunol 12: 37, 2011.

11. Strober W: Trypan Blue exclusion test of cell viability. Curr Protoc Immunol: Appendix 3: Appendix 3B, 2001.

12. Livak KJ and Schmittgen TD: Analysis of relative gene expression data using real-time quantitative PCR and the 2(-Delta Delta C(T)) Method. Methods 25: 402-408, 2001.

13. Field SL, Dasgupta T, Cummings $M$ and Orsi NM: Cytokines in ovarian folliculogenesis, oocyte maturation and luteinisation. Mol Reprod Dev 81: 284-314, 2014.

14. Ojeda-Ojeda M, Murri M, Insenser M and Escobar-Morreale HF: Mediators of low-grade chronic inflammation in polycystic ovary syndrome (PCOS). Curr Pharm Des 19: 5775-5791, 2013.

15. Ianchiı̌ RI, Voznesens'ka TIu and Shepel' OA: Cytokines and their role in reproductive system. Fiziol Zh 53: 82-90, 2007 (in Ukrainian)

16. Luo J, Elwood F, Britschgi M, Villeda S, Zhang H, Ding Z, Zhu L, Alabsi H, Getachew R, Narasimhan R, et al: Colony-stimulating factor 1 receptor (CSF1R) signaling in injured neurons facilitates protection and survival. J Exp Med 210: 157-172, 2013.

17. Zhang Z, Fang $Q$ and Wang J: Involvement of macrophage colony-stimulating factor (M-CSF) in the function of follicular GCs. Fertil Steril 90: 749-754, 2008.

18. Kawamura K, Chen Y, Shu Y, Cheng Y, Qiao J, Behr B, Pera RA and Hsueh AJ: Promotion of human early embryonic development and blastocyst outgrowth in vitro using autocrine/paracrine growth factors. PLoS One 7: e49328, 2012.

19. Araki M, Fukumatsu Y, Katabuchi H, Shultz LD, Takahashi K and Okamura H: Follicular development and ovulation in macrophage colony-stimulating factor-deficient mice homozygous for the osteopetrosis (op) mutation. Biol Reprod 54: 478-484, 1996.

20. Sweet MJ and Hume DA: CSF-1 as a regulator of macrophage activation and immune responses. Arch Immunol Ther Exp (Warsz) 51: 169-177, 2003.

21. Chitu V and Stanley ER: Colony-stimulating factor-1 in immunity and inflammation. Curr Opin Immunol 18: 39-48, 2006.

22. Schönlau F, Schlesiger C, Ehrchen J, Grabbe S, Sorg C and Sunderkötter C: Monocyte and macrophage functions in M-CSF-deficient op/op mice during experimental leishmaniasis. J Leukoc Biol 73: 564-573, 2003.

23. Zhang Z, Fang $\mathrm{Q}$ and Wang J: Involvement of macrophage colony-stimulating factor (M-CSF) in the function of follicular GCs. Ferti 1Steril 90: 749-754, 2008.

24. Chakraborty P and Roy SK: Expression of FSH receptor in the hamster ovary during perinatal development. Mol Cell Endocrinol 400: 41-47, 2015.

25. Lee AW, Mao Y, Penninger JM and Yu S: Gab2 promotes colony-stimulating factor 1-regulated macrophage expansion via alternate effectors at different stages of development. Mol Cell Biol 31: 4563-4581, 2011.

26. Popa-Wagner A, Stöcker K, Balseanu AT, Rogalewski A, Diederich K, Minnerup J, Margaritescu C and Schäbitz WR: Effects of granulocyte-colony stimulating factor after stroke in aged rats. Stroke 41: 1027-1031, 2010. 